\title{
KFUPM-KAUST Red Sea model: Digital viscoelastic depth model and synthetic seismic data set
}

\author{
Abdullatif A. Al-Shuhail ${ }^{1}$, Wail A. Mousa ${ }^{1}$, and Tariq Alkhalifah ${ }^{2}$
}

\section{Abstract}

The Red Sea is geologically interesting due to its unique structures and abundant mineral and petroleum resources, yet no digital geologic models or synthetic seismic data of the Red Sea are publicly available for testing algorithms to image and analyze the area's interesting features. This study compiles a $2 \mathrm{D}$ viscoelastic model of the Red Sea and calculates a corresponding multicomponent synthetic seismic data set. The models and data sets are made publicly available for download. We hope this effort will encourage interested researchers to test their processing algorithms on this data set and model and share their results publicly as well.
Table 1. Summary of some well-known salt models.

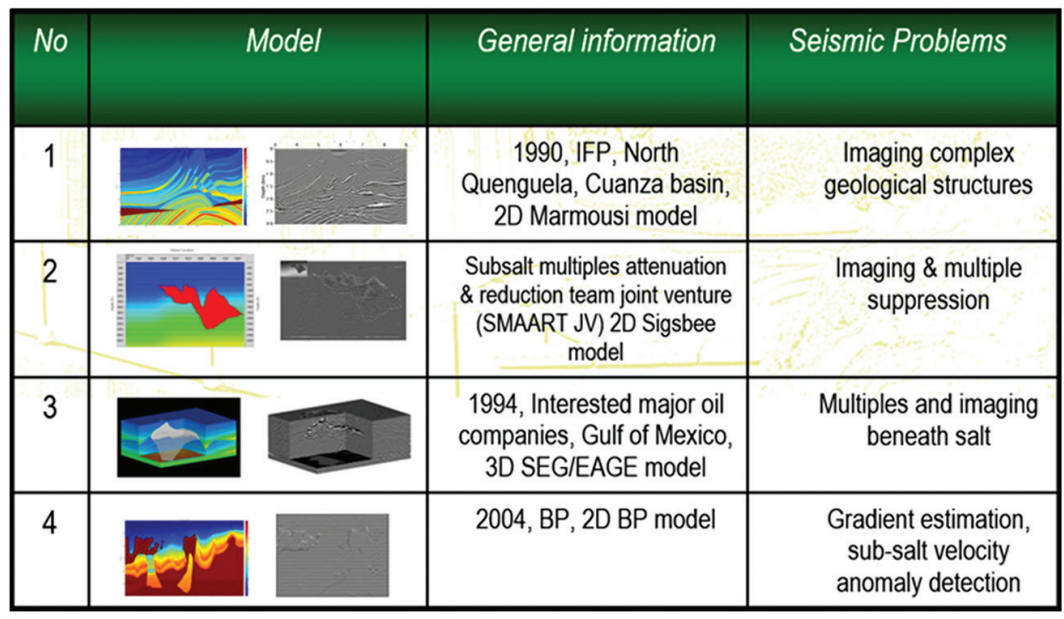

\section{Introduction}

Many velocity models exist, such as the 3D SEG/EAGE model and the 2D Marmousi, Sigsbee, and BP models (Table 1). All these models were generated to address issues encountered when attempting to invert subsurface images in seismically challenging areas at different locations of the world.

This paper is dedicated to presenting a 2D viscoelastic depth model representative of the northern Red Sea onshore region that includes its main seismic challenges and using this model to generate a corresponding $2 \mathrm{D}$ synthetic viscoelastic multicomponent seismic data set that can be used for testing existing and newly developed seismic imaging and processing algorithms. The viscoelastic model includes the following depth sections:
1. P-wave velocity $\left(V_{\mathrm{P}}\right)$
2. S-wave velocity $\left(V_{\mathrm{S}}\right)$
3. Density $(\rho)$
4. P-wave quality factor $\left(\mathrm{Q}_{\mathrm{P}}\right)$
5. S-wave quality factor $\left(\mathrm{Q}_{\mathrm{s}}\right)$

The above model is used to generate the following $2 \mathrm{D}$ synthetic viscoelastic multicomponent seismic data sets:

1. Vertical component data

2. Horizontal component data

Digital horizons, depth sections of the viscoelastic model, and synthetic multicomponent seismic data sets can be downloaded freely from the following link: http://wiki.seg.org/ wiki/KFUPM-KAUST_Red_Sea_model. All files are provided in Seismic Un*x (SU) format except for the horizons and faults, which are in comma-separated-values (CSV) format.

\section{Geologic setting of the Red Sea}

The Red Sea is located west of the Arabian Peninsula and extends for about $2000 \mathrm{~km}$ from the Gulf of Aqaba in the north to the Bab al-Mandeb Strait in the south (Figure 1). Its width varies, reaching a maximum of $370 \mathrm{~km}$ in its middle and a minimum of $30 \mathrm{~km}$ in the Bab al-Mandeb Strait. It is a rift system that started $30 \mathrm{Ma}$ ago and continues fragmenting the Arabian-Nubian Shield (Ligi et al., 2011) (Figure 2). It occupies a long northwest-trending basin between the African and Arabian shields and is characterized by steep walls in the axial trough and irregular seafloor topography (Coleman, 1974). The axial trough shows changes in offsets, high-temperature brines, and hydrothermal sediments.

The Red Sea geology is important to study because it is considered an evolving young ocean, and studying it gives insight into the early stages of mature oceans (Ligi et al., 2011). Furthermore, it contains considerable mineral resources on its floor such as zinc, copper, silver, and gold (World Ocean Review, n.d.). Additionally, fair amounts of petroleum resources have been discovered offshore and onshore the Red Sea, and more exploration is currently taking place in it (Hughes and Johnson, 2005). A major exploration target in the Red Sea is a thick prerift carbonate layer that is usually overlain by a thick salt layer. A major challenge for the seismic imaging of this target is the distortion of seismic waves by the salt layer. In this paper, we aim to present a high-resolution $2 \mathrm{D}$ viscoelastic model and synthetic seismic data set to researchers interested in seismic imaging of the Red Sea.

Several studies show that lithostratigraphy and structures vary greatly along the Red Sea coast because of the various phases of rifting it experienced since its inception. Details of the tectonic 
evolution of the Red Sea are covered in Bosworth et al. (2005), while its lithostratigraphy is covered in detail by Hughes and Johnson (2005). Because of this variation, we had to pick a specific locality to generate a representative Red Sea model. The Midyan area in the northeastern part of the Red Sea is selected because it includes the main seismic challenges, and literature is abundant with information about the lithological, structural, and seismic properties of this area (Al-Dulaijan and Chimblo, 1994; Mougenot and Al-Shakhis, 1998; Kelamis et al., 1999; Alkhalifah, 2005; Tubbs et al., 2014).

\section{Development of digital depth models}

The geologic column in the Midyan area of the Red Sea can be divided into the following three sections from top to bottom (Table 2):

- Postsalt section at the top: this section consists of clastic sediments with generally low seismic velocities and no petroleum resources. This section can be subdivided into three main layers:

- Layer 1 at the top of the section: a clastic weathering layer with an average $\mathrm{P}$-wave velocity of vp1 $=1400 \mathrm{~m} / \mathrm{s}$ and an average thickness $\mathrm{z} 1=600 \mathrm{~m}$.

- Layer 2 in the middle of the section: a clastic layer with a vertically varying $\mathrm{P}$-wave velocity profile given as vp $2(\mathrm{z})=$ $2000+0.4(z-z 1)$, where $z$ indicates the depth of that point and $\mathrm{z} 1$ indicates the thickness of layer 1 at that point.

- Layer 3 at the bottom of the section: another clastic layer with a vertically varying $\mathrm{P}$-wave velocity profile given as $v p 3(z)=v p 2(z 2)+0.6(z-z 2)$, where $z 2$ indicates the depth to the bottom of layer 2 at that point.

- Salt section: this section is composed of a thick salt layer (layer 4) with a P-wave velocity of vp $4=4500 \mathrm{~m} / \mathrm{s}$.

- Presalt section: this section consists of two main units:

- Layer 5 at the top of the section: a carbonate layer with a P-wave velocity of vp $5=3900 \mathrm{~m} / \mathrm{s}$. This layer is thought to have considerable petroleum resources (Alsharhan and Salah, 1997).

- Layer 6 at the bottom of the section: basement rocks with a P-wave velocity of vp $6=5300 \mathrm{~m} / \mathrm{s}$.

The main horizons and faults of the model were determined from the geologic sections and descriptions given by Mougenot and Al-Shakhis (1998) and Kelamis et al. (1999). Five horizons and four faults were defined and digitized at a horizontal interval of $5 \mathrm{~m}$. Layers 1, 4, 5, and 6 have constant P-wave velocities, while layers 2 and 3 have linear vertical $\mathrm{P}$-wave velocity profiles as described above. The compilation of these horizons and faults resulted in a 2D model with dimensions of $3500 \mathrm{~m}$ vertically and $11,800 \mathrm{~m}$ horizontally. Figure 3 shows the horizons and faults of the model.

The $\mathrm{P}$-wave velocities of the model were determined from Mougenot and Al-Shakhis (1998) and Kelamis et al. (1999). The

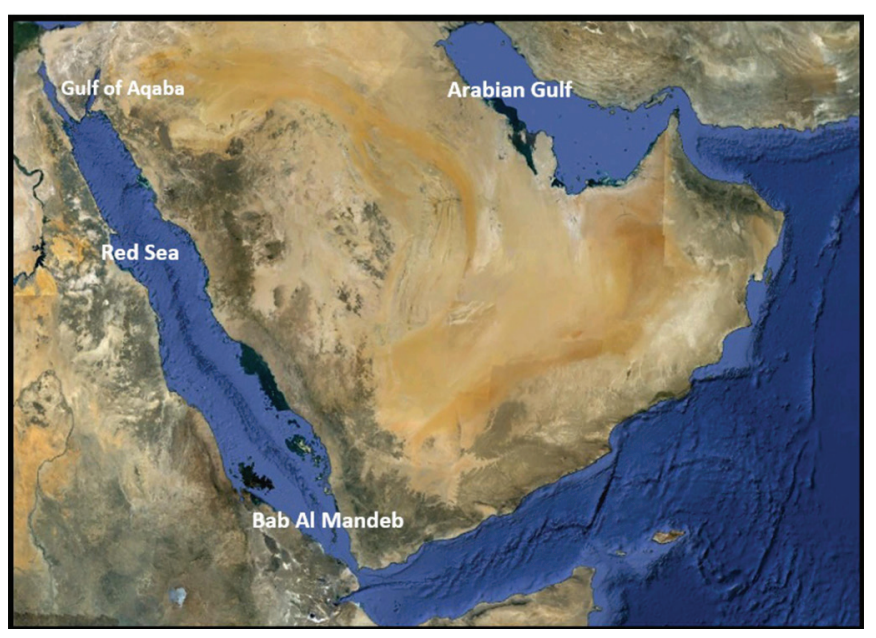

Figure 1. Satellite image showing the Red Sea, the Arabian Peninsula and the Arabian Gulf (image courtesy of Google Earth).

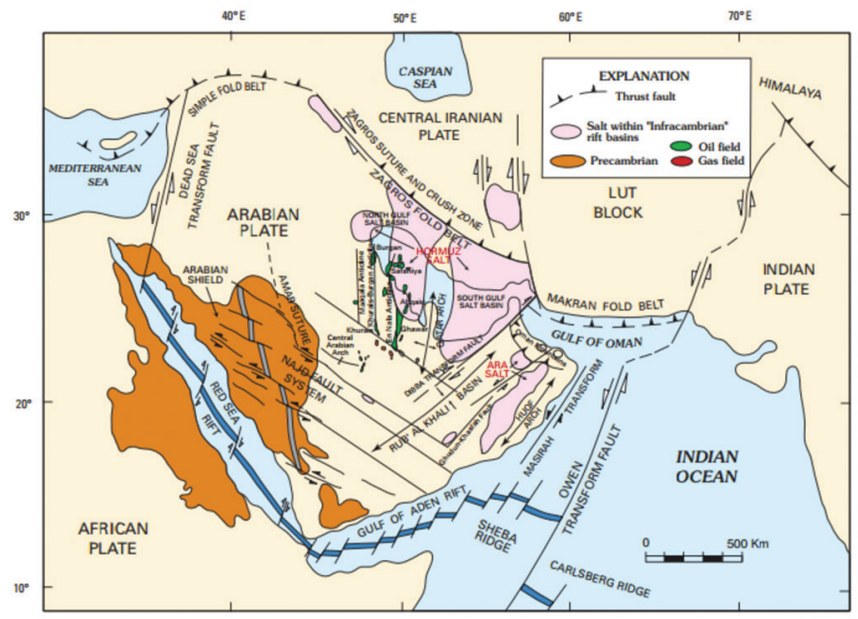

Figure 2. General tectonic setting of Arabian plate and Red Sea showing the Red Sea rift separating the Arabian and Nubian Shields (image courtesy of https:// en.wikipedia.org/wiki/Persian_Gulf_Basin, shared under the CC BY-SA 3.0 Unported License).

Table 2. P- and S-wave velocities, P- and S-wave quality factors, and densities of layers of the Red Sea model.

\begin{tabular}{|c|c|c|c|c|c|c|}
\hline Layer & Lithology & P-wave velocity (m/sec) & Density $\left(\mathrm{kg} / \mathrm{m}^{3}\right)$ & S-wave velocity (m/sec) & P-wave quality factor & S-wave quality factor \\
\hline 1 & soil $^{\mathrm{e}}$ & vp1=1400 e & $\mathrm{d} 1=1750^{\mathrm{a}}$ & vs $1=270^{a}$ & $\mathrm{Qp} 1=\operatorname{sqrt}(\mathrm{vp} 1)^{\mathrm{d}}$ & Qs1=sqrt(vs1) ${ }^{\mathrm{d}}$ \\
\hline 2 & clastics $^{e}$ & $\operatorname{vp} 2(z)=2000+0.4^{*}\left(z-z 1^{*}\right)^{e}$ & $\mathrm{~d} 2(\mathrm{z})=310^{*} \mathrm{vp} 2(\mathrm{z})^{\wedge} 0.25^{\mathrm{b}}$ & vs $2=0.806^{*}$ vp $2(z)-856^{b}$ & $\mathrm{Qp} 2=\operatorname{sqrt}(\mathrm{vp} 2)^{\mathrm{d}}$ & Qs $2=\operatorname{sqrt}(\mathrm{vs} 2)^{\mathrm{d}}$ \\
\hline 3 & clastics $^{\mathrm{e}}$ & $\mathrm{vp} 3(\mathrm{z})=\mathrm{v} 2(\mathrm{z} 2)+0.6^{*}\left(\mathrm{z}-\mathrm{z} 2^{* *}\right)^{\mathrm{e}}$ & $\mathrm{d} 3(\mathrm{z})=310^{*} \mathrm{vp} 3(\mathrm{z})^{\wedge} 0.25^{\mathrm{b}}$ & vs $3=0.806^{*}$ vp $3(z)-856^{b}$ & Qp3=sqrt(vp3) ${ }^{d}$ & Qs3=sqrt $(\text { vs3 })^{\mathrm{d}}$ \\
\hline 4 & salt $^{\mathrm{e}}$ & $\mathrm{vp} 4=4500^{\mathrm{e}}$ & $\mathrm{d} 4=2170^{\mathrm{c}}$ & vs $4=2250^{c}$ & $\mathrm{Qp} 4=\operatorname{sqrt}(\mathrm{vp} 4)^{\mathrm{d}}$ & Qs $4=\operatorname{sqrt}(\mathrm{vs} 4)^{\mathrm{d}}$ \\
\hline 5 & carbonates $^{\mathrm{e}}$ & $\mathrm{vp} 5=3900^{\mathrm{e}}$ & $\mathrm{d} 5=2450^{\mathrm{b}}$ & vs $5=2050^{b}$ & $\mathrm{Qp} 5=\operatorname{sqrt}(\mathrm{vp} 5)^{\mathrm{d}}$ & Qs5=sqrt(vs5) ${ }^{\mathrm{d}}$ \\
\hline 6 & basement $^{\mathrm{e}}$ & vp6 $=5300^{\mathrm{e}}$ & $\mathrm{d} 6=2650^{\mathrm{a}}$ & vs $6=3120^{a}$ & Qp6=sqrt(vp6) ${ }^{d}$ & Qs6=sqrt(vs6) ${ }^{\mathrm{d}}$ \\
\hline
\end{tabular}

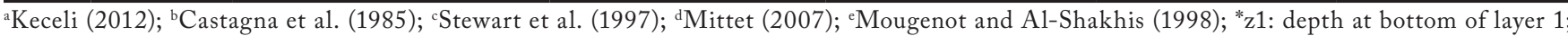

${ }^{* *} \mathrm{z} 2$ : depth at bottom of layer 2 
$\mathrm{S}$-wave velocities were calculated from these $\mathrm{P}$-wave velocities using $\mathrm{P}$-wave/S-wave velocity relations for each lithology published in Castagna et al. (1985). Likewise, the densities were calculated from the P-wave velocities using Gardner's velocity-density relations (Gardner et al., 1974). The P-wave and S-wave quality factors were calculated by taking the square root of the corresponding value of the $\mathrm{P}$-wave and $\mathrm{S}$-wave velocity, respectively (Mittet, 2007). Table 2 shows the values and relations used to calculate the various properties of the viscoelastic model. Details of the various properties of the viscoelastic model are given in Figure 4. To reduce computational costs, we generate only a 2D model and synthetic seismic data set. Although we honor viscoelastic effects, we ignore anisotropy for the sake of simplicity.

\section{Generation of synthetic seismic data}

After establishing the viscoelastic properties of the model, we decimate them to prepare them for the generation of synthetic seismic data using a finite difference method (FDM). Many FD parameters depend on the frequency content of the source wavelet. We use a zero-phase Ricker wavelet with a peak frequency of $15 \mathrm{~Hz}$. Although higher-frequency wavelets are generally used in practice (e.g., $30 \mathrm{~Hz}$ ), we use this low-frequency wavelet to simulate viscoelastic absorption effects at the reservoir level.

When using FD solutions of the wave equation, it is important to select a grid spacing that avoids numerical dispersion. A general rule for a dispersion-free FD scheme that is accurate up to the fourth order in space and second order in time is to have five or more grid points per minimum wavelength:

$$
\Delta x=\Delta z \leq \frac{V_{\min }}{5 f_{\max }},
$$

where $\Delta x$ and $\Delta z$ are the grid sizes along the $x$ axis and $z$ axis, respectively, which are assumed equal. The minimum $\mathrm{S}$-wave velocity in our model is $270 \mathrm{~m} / \mathrm{s}$. The maximum frequency of our wavelet is $45 \mathrm{~Hz}$, which is the frequency at which the amplitude spectrum of the source wavelet drops below $1 \%$ of its peak at $15 \mathrm{~Hz}$ (Thorbecke, 2016). This resulted in a grid spacing $\Delta x=\Delta z=1.2 \mathrm{~m}$, which we relaxed to $1.25 \mathrm{~m}$ to reduce computational costs, although this may introduce $\mathrm{S}$-wave dispersion in the weathering layer (Martin et al., 2006).

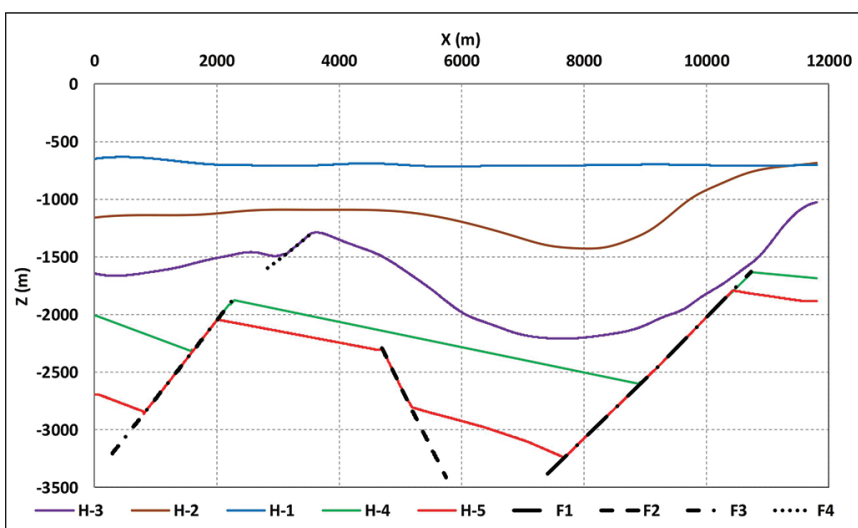

Figure 3. Horizons and faults of the Red Sea model. H-1 to H-5 indicate horizons, while F-1 to F-4 indicate faults.
In addition to grid spacing, FD time-marching step $(\Delta t)$ must satisfy the Courant-Friedrichs-Lewy (CFL) stability condition of convergence given as (Thorbecke, 2016)

$$
\Delta t \leq \frac{0.606 \Delta x}{V_{\max }},
$$

a

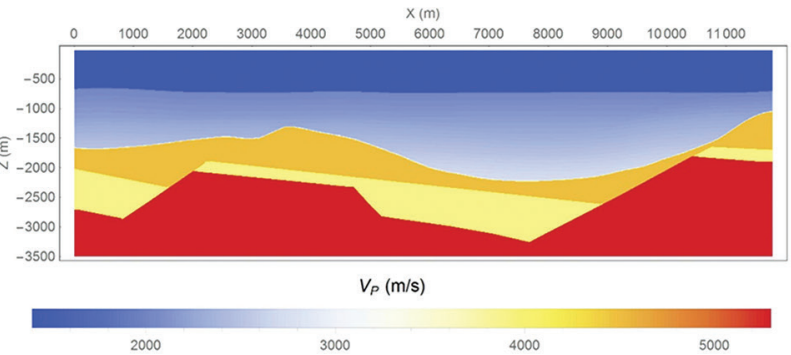

b

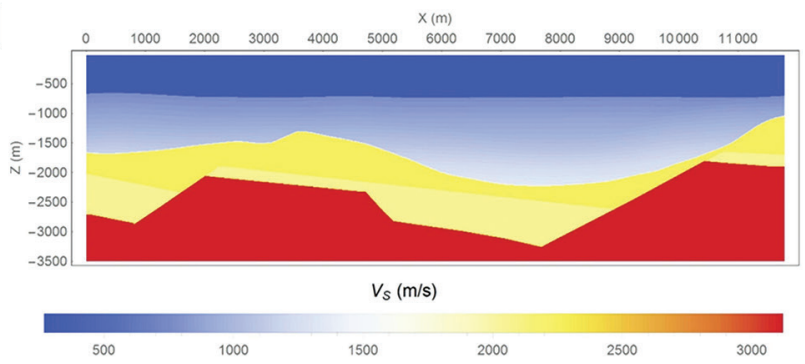

C

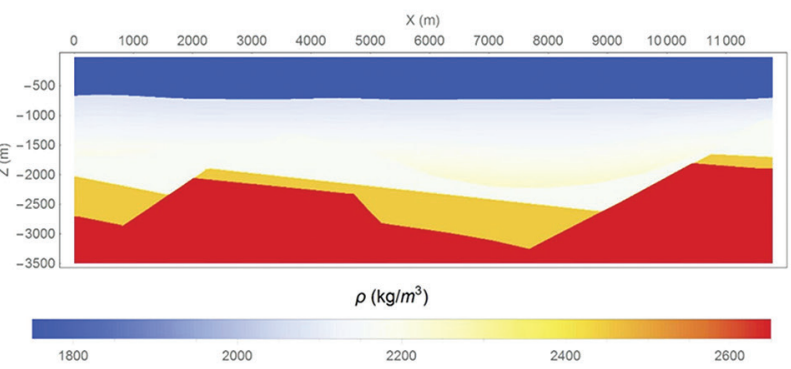

d

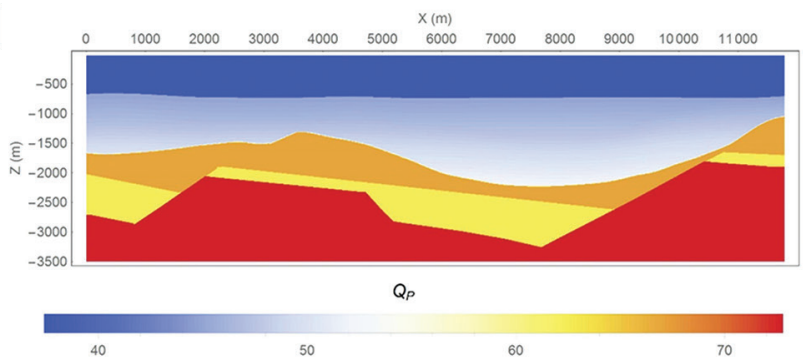

e

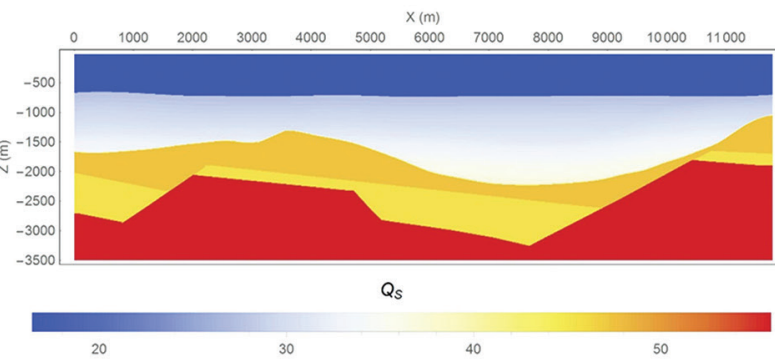

Figure 4. (a) P-wave velocity model. (b) S-wave velocity model. (c) Density model. (d) P-wave quality factor model. (e) S-wave quality factor model. 
where $V_{\max }$ is the maximum $\mathrm{P}$-wave velocity in the model. Using the velocity of basement rock $\left(V_{\max }=5300 \mathrm{~m} / \mathrm{s}\right)$ and $\Delta x=1.2 \mathrm{~m}$, we calculate a time step $\Delta t=0.14 \mathrm{msec}$. We use the fdelmodc source code described in Thorbecke (2016) to generate the viscoelastic synthetic seismic data set.

For the model boundaries, we use an absorbing boundary condition with a taper of 375 grid points for the bottom, left, and right boundaries of the model and a free surface for the top boundary. The above taper length is calculated using the following rule (Thorbecke, 2016):

$$
\text { Taper length }=\frac{4 V_{\max }}{\Delta x \times f_{\max }} .
$$

For data acquisition, we use a conventional 2D land seismic survey geometry. Sources span the whole model starting from $x=0 \mathrm{~m}$ to $x=11,800 \mathrm{~m}$ with a source every $50 \mathrm{~m}$. Receivers also span the whole model starting from $x=0 \mathrm{~m}$ to $x=11,800 \mathrm{~m}$ but with a receiver every $25 \mathrm{~m}$. Sources and receivers were buried $15 \mathrm{~m}$ below the surface because they could not be put on the free surface (Thorbecke, 2016). Offsets ranged from a minimum of $0 \mathrm{~m}$ to a maximum of $11,800 \mathrm{~m}$, which is suitable for many seismic data processing and analysis studies including amplitude variation with offset (AVO), imaging, and velocity analysis. Table 2 summarizes the parameters used for the synthetic seismic data generation.

Two synthetic viscoelastic seismic data sets were generated: vertical and horizontal components. To simulate ambient noise effects, additive Gaussian random noise with zero mean and $10 \%$ standard deviation was added to the synthetic data sets. Figure 5 shows sample vertical-component synthetic seismic shot records, while Figure 6 shows sample horizontal-component synthetic seismic shot records. On all parts of Figures 5 and 6, the horizontal axis is labeled in trace (receiver) number, while the vertical axis is labeled in time in msec and no amplitude gain applied. Some obvious events are indicated on Figure 5a. Many other more

complicated events can be observed on Figures 5 and 6 due to complex structures and velocity profiles of the model.

\section{Summary}

Although the Red Sea is an important basin due to its unique tectonic history and mineral and petroleum resources, there exists no digital seismic model of it. We compiled a 2D viscoelastic seismic model of the northern Red Sea region for that purpose and generated a corresponding multicomponent synthetic seismic data set. Despite the small number of layers in the model, the synthetic seismic data set seems challenging to invert especially below the salt layer. We made the generated models and synthetic data sets publicly available

Table 3. Parameters used to generate the synthetic seismic data set.

\begin{tabular}{|l|l|}
\hline Parameter & Value \\
\hline Source wavelet & $15 \mathrm{~Hz}$ zero-phase Ricker \\
\hline $\begin{array}{l}\text { Time sampling interval for } \\
\text { FDM calculation }\end{array}$ & $0.14 \mathrm{msec}$ \\
\hline $\begin{array}{l}\text { Square-grid size for FDM } \\
\text { calculation }\end{array}$ & $1.25 \mathrm{~m}$ \\
\hline Receiver spacing & $25 \mathrm{~m}$ \\
\hline Shot spacing & $50 \mathrm{~m}$ \\
\hline $\begin{array}{l}\text { Recording time sampling } \\
\text { interval }\end{array}$ & $4.06 \mathrm{msec}$ \\
\hline Total recording time & $4.99786 \mathrm{sec}$ \\
\hline Total number of receivers & 473 \\
\hline Receivers $x$ axis & 0 to $11800 \mathrm{~m}$ \\
\hline Receivers $z$ axis & $-15 \mathrm{~m}$ \\
\hline Shots $x$ axis & 0 to $11800 \mathrm{~m}$ \\
\hline Shots $z$ axis & $-15 \mathrm{~m}$ \\
\hline Offset range & 0 to $11800 \mathrm{~m}$ \\
\hline Total number of shots & 237 shots \\
\hline
\end{tabular}
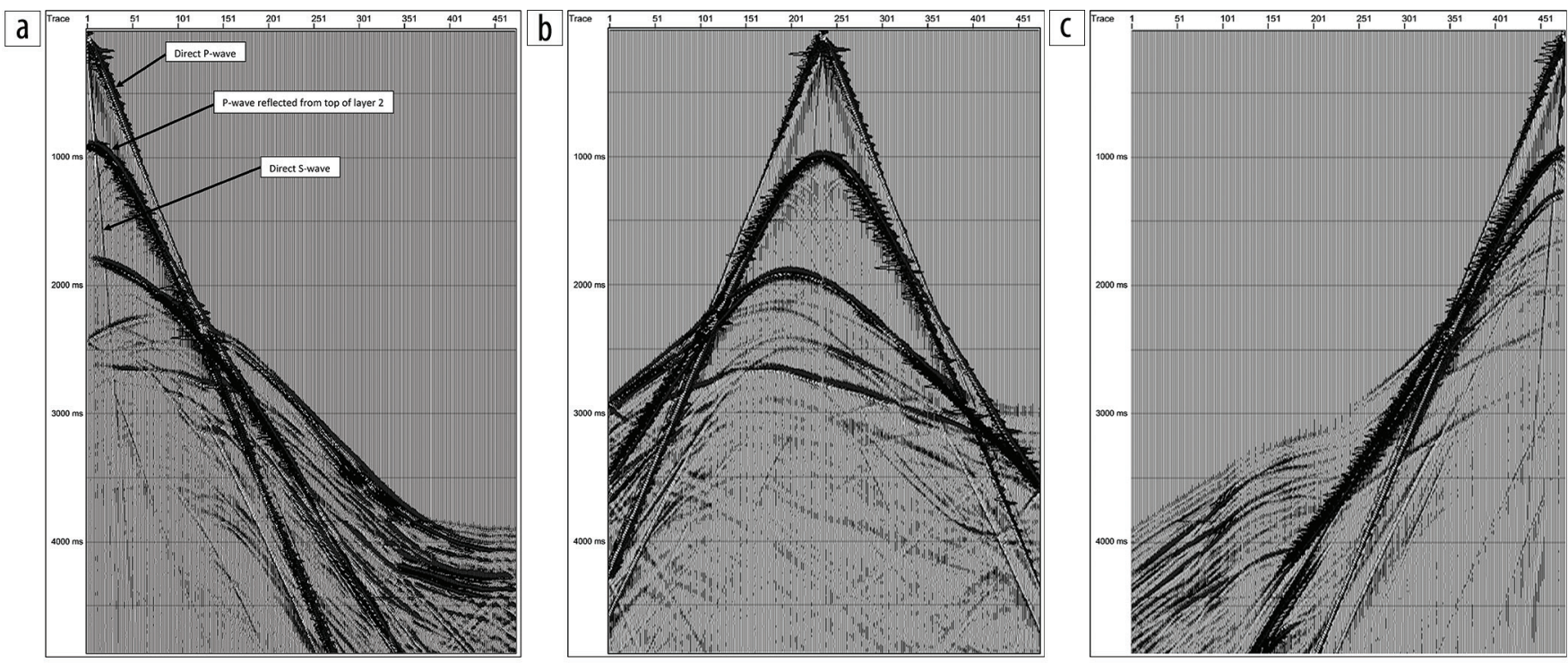

Figure 5. (a) Vertical component of shot point number $1(x=0 \mathrm{~m})$ of the synthetic data. (b) Vertical component of shot point number $118(x=5850 \mathrm{~m})$ of the synthetic data. (c) Vertical component of shot point number $237(x=11,800 \mathrm{~m})$ of the synthetic data. 

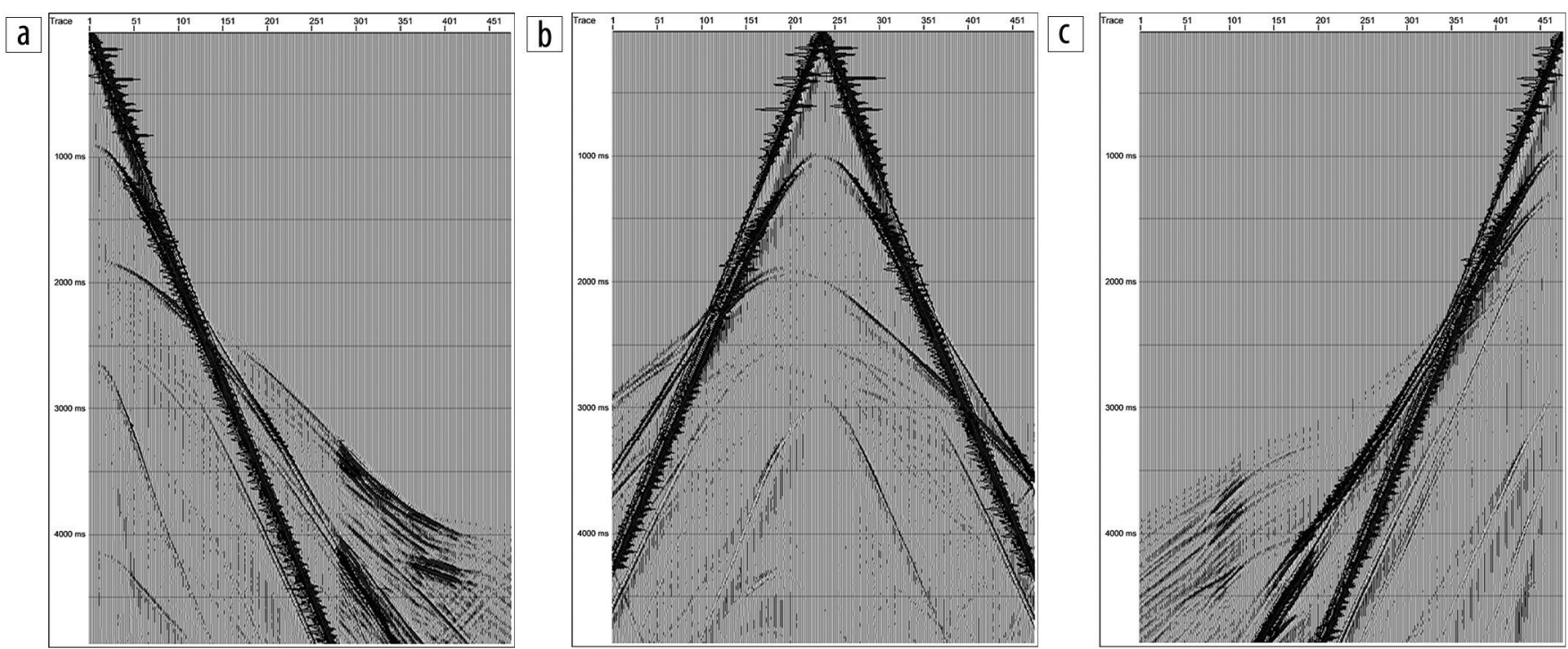

Figure 6. (a) Horizontal component of shot point number $1(x=0 \mathrm{~m})$ of the synthetic data. (b) Horizontal component of shot point number $118(x=5850 \mathrm{~m})$ of the synthetic data. (c) Horizontal component of shot point number $237(x=11,800 \mathrm{~m})$ of the synthetic data.

via a dedicated online folder and invite researchers to test their algorithms on these data sets and models and share their results with us. In the future, we plan to extend the models to 3D geometry and include more structural, anisotropic, and fluid effects. TLE:

\section{Acknowledgments}

We wish to thank King Abdullah University of Science and Technology (KAUST) for supporting this research under grant number EE002356. A.A. and W.M. thank King Fahd University of Petroleum and Minerals (KFUPM) for its continuous support.

Corresponding author: ashuhail@kfupm.edu.sa

\section{References}

Alkhalifah, T., 2005, $\tau$-migration and velocity analysis: application to data from the Red Sea: Geophysical Prospecting, 53, no. 5, 643-653, http://dx.doi.org/10.1111/j.1365-2478.2005.00493.x.

Alsharhan, A. S., and M. G. Salah, 1997, Lithostratigraphy, sedimentology and hydrocarbon habitat of the pre-Cenomanian Nubian sandstone in the Gulf of Suez oil province, Egypt: GeoArabia, 2, no. 4, 385-400.

Al-Dulaijan, A., and R. Chimblo, 1994, Implementing innovative geophysical techniques for exploration and field development in Saudi Arabia: $14^{\text {th }}$ World Petroleum Congress, WPC, Proceedings, 119-127.

Bosworth, W., P. Huchon, and K. McClay, 2005, The Red Sea and Gulf of Aden basins: Journal of African Earth Sciences, 43, no. 1-3, 334-378, http://dx.doi.org/10.1016/j. jafrearsci.2005.07.020.

Castagna, J. P., M. L. Batzle, and R. L. Eastwood, 1985, Relationships between compressional-wave and shear-wave velocities in clastic silicate rocks: Geophysics, 50, no. 4, 571-581, http://dx.doi. org/10.1190/1.1441933.

Coleman, R. G., 1974, Geologic background of the Red Sea, in R. B. Whitmarsh, O. E. Weser, and D. A. Ross, eds., Initial Reports of the Deep See Drilling Project: IODP, 813-820.
Gardner, G. H. F., L. W. Gardner, and A. R. Gregory, 1974, Formation velocity and density - The diagnostic basics for stratigraphic traps: Geophysics, 39, no. 6, 770-780, http://dx.doi.org/10.1190/1.1440465.

Hughes, G. W. G., and R. S. Johnson, 2005, Lithostratigraphy of the Red Sea region: GeoArabia, 10, no. 3, 49-126.

Keceli, A., 2012, Soil parameters which can be determined with seismic velocities: Jeofizik, 16, 17-29.

Kelamis, P., A. Berkhout, D. Verschuur, and R. Romijn, 1999, Common focus point technology - An example from the Red Sea area of Saudi Arabia: Saudi Aramco Journal of Technology, Fall 1999, 32-38.

Ligi, M., E. Bonatti, F. Tontini, A. Cipriani, L. Cocchi, A. Schettino, G. Bortoluzzi, V. Ferrante, S. Khalil, N. Mitchell, and N. Rasul, 2011, Initial burst of oceanic crust accretion in the Red Sea due to edge-driven mantle convection: Geology, 39, no. 11, 1019-1022, http://dx.doi.org/10.1130/G32243.1.

Martin, G., R. Wiley, and K. Marfurt, 2006, Marmousi2: An elastic upgrade for Marmousi: The Leading Edge, 25, no. 2, 156-166, http://dx.doi.org/10.1190/1.2172306.

Mittet, R., 2007, A simple design procedure for depth extrapolation operators that compensate for absorption and dispersion: Geophysics, 72, no. 2, S105-S112, http://dx.doi.org/10.1190/1.2431637.

Mougenot, D. and A. Al-Shakhis, 1998, Depth imaging a pre-salt faulted block: A case study from the Midyan basin (Red Sea): Saudi Aramco Journal of Technology, Fall 1998, 2-10.

Stewart, R., H. Bland, Q. Zhang, and F. Guthoff, 1997, Average versus interval $V_{\mathrm{P}} / V_{\mathrm{S}}$ : Canadian Journal of Exploration Geophysics, 33, 29-31.

Thorbecke, J., 2016, Finite-difference wavefield modeling, https:// janth.home.xs4all.nl/ Software/Software.html, accessed 23 July 2016.

Tubbs, R. Jr., H. Fouda, A. Afifi, N. Raterman, G. Hughes, and Y. Fadolalkarem, 2014, Midyan Peninsula, northern Red Sea, Saudi Arabia: Seismic imaging and regional interpretation: GeoArabia, 19, no. 3, 165-184.

World Ocean Review, http://worldoceanreview.com/en/wor-3-overview/mineral-resources/massive-sulphides/metal-rich-brines-inthe-red-sea/, accessed 14 August 2016. 